\title{
Simultaneous inversion of surface deformation and gravity changes by means of extended bodies with a free geometry: Application to deforming calderas
}

\begin{abstract}
Antonio G. Camacho, ${ }^{1}$ Pablo J. González, ${ }^{2}$ José Fernández, ${ }^{1}$ and Giovanna Berrino ${ }^{3}$
Received 16 December 2010; revised 21 June 2011; accepted 24 July 2011; published 5 October 2011.

[1] Changes in gravity and/or surface deformation are often associated with volcanic activity. Usually, bodies with simple geometry (e.g., point sources, prolate or oblate spheroids) are used to model these signals considering anomalous mass and/or pressure variations. We present a new method for the simultaneous, nonlinear inversion of gravity changes and surface deformation using bodies with a free geometry. Assuming simple homogenous elastic conditions, the method determines a general geometrical configuration of pressure and density sources. These sources are described as an aggregate of pressure and density point sources, fitting the whole data set (given some regularity conditions). The approach works in a growth step-by-step process that allows us to build very general geometrical configurations. The methodology is validated against an ellipsoidal body with anomalous pressure and a parallelepiped body with anomalous density, buried in an elastic medium. The simultaneous inversion of deformation and gravity values permits a good reconstruction of the assumed bodies. Finally, the inversion method is applied to the interpretation of gravity, leveling, and interferometric synthetic aperture radar (InSAR) data from the volcanic area of Campi Flegrei (Italy) for the period 1992-2000. For this period, a model with no significant mass change and an extended decreasing pressure region satisfactorily fits the data. The pressure source is located at about $\sim 1500 \mathrm{~m}$ depth, and it is interpreted as corresponding to the dynamics of the shallow (depth 1-2 km) hydrothermal system confined to the caldera fill materials.
\end{abstract}

Citation: Camacho, A. G., P. J. González, J. Fernández, and G. Berrino (2011), Simultaneous inversion of surface deformation and gravity changes by means of extended bodies with a free geometry: Application to deforming calderas, J. Geophys. Res., 116, B10401, doi:10.1029/2010JB008165.

\section{Introduction}

[2] Calderas are highly heterogeneous volcanic systems in terms of local stress-field and volcano-structural features. In such complex environments, surface expressions for magma replenishment or withdrawal and dynamic changes in hydrothermal systems mimic and superimpose on each other at spatial and temporal scales, making the characterization of periods of unrest difficult [e.g., Eggers, 1987; Bonafede and Mazzanti, 1998]. Geophysical and geodetic studies can identify at least three different levels of reservoirs capable of producing mass or pressure changes [Gottsmann and Battaglia, 2008]: (1) hydrothermal reservoirs (few kilometers depth), (2) midcrustal reservoirs (melt and aqueous fluids), and (3) deep reservoirs (underplating).

\footnotetext{
${ }^{1}$ Instituto de Astronomía y Geodesia, CSIC-UCM, Madrid, Spain.

${ }^{2}$ Department of Earth Sciences, University of Western Ontario, London, Ontario, Canada.

${ }^{3}$ Istituto Nazionale di Geofisica e Vulcanologia, Sezione di Napoli, Osservatorio Vesuviano, Naples, Italy.

Copyright 2011 by the American Geophysical Union. 0148-0227/11/2010JB008165
}

[3] Operative geodetic techniques, useful for the characterization of volcanic processes, are mainly microgravity and surface deformation control. Temporal gravity changes $(d g)$ and surface deformation $(d x, d y, d z)$ can provide fundamental insight into processes that involve mass redistribution and pressure changes within volcanic structures. Accurate gravity data from control networks are collected by time-lapse surveys [Battaglia et al., 2008], and then significant temporal gravity changes $(d g)$ can be detected. In addition, repeated leveling surveys allow us to detect changes in elevation for benchmarks. Accuracies of observed gravity changes are usually about $10 \mu \mathrm{Gal}\left(1 \mu \mathrm{Gal}=10^{-8} \mathrm{~m} \mathrm{~s}^{-2}\right)$ and a rather better accuracy level comes from altitude changes. Ground deformation using repeated and nearly simultaneous Global Positioning System (GPS) observations and permanent stations can detect temporal changes of three-dimensional (3-D) positions $(d x, d y, d z)$ for the observed benchmarks within an accuracy of about a few millimeters, and differential interferometric synthetic aperture radar (InSAR) techniques can produce nearly spatially continuous maps for surface deformation along the line of sight (LOS) for selected epochs within an accuracy level of some few millimeters [Gabriel et al., 1989]. 
[4] A quantitative interpretation of geodetic data may require an inversion approach, constrained by general hypotheses, to constrain source processes (mass and pressure variations) at depths. A number of analytical and numerical mathematical models, available in the literature, can be used to fit ground deformation and gravity data to infer source location [see e.g., Battaglia and Hill, 2009]. The interpretative discussion of results aims to offer a better understanding of the volcano's behavior and is also a basic aspect for volcano monitoring strategy and helping decision makers' actions during crisis situations.

[5] The source approach for the data fit is usually based on spherical, ellipsoidal, or general extended causative bodies. Fault, dike, laminar, or cylindrical structures are sometimes employed. Moreover, the mathematical model for the source structure must consider some elastic properties to account for the deformation phenomena. The usual analytical models assume an elastic, homogeneous and isotropic crust, but they can take into account effects from several source geometries, topography relief, and gravity background [e.g., Williams and Wadge, 1998; Charco et al., 2007; Battaglia and Hill, 2009].The elastic-gravitational model of Rundle [1980, 1982] and Fernández and Rundle [1994a, 1994b] is a refinement of purely elastic models and can interpret gravity and deformation changes in active volcanic zones [Charco et al., 2006].

[6] Some published studies combine several geodetic data to produce integrated inversion models. For instance, Vasco et al. [2007] combine leveling, GPS, and InSAR data $(\boldsymbol{u})$ to infer volume change $(v)$ below the Yellowstone volcanic system. They fit an anomalous volume change distribution $v$ by working from the linear model equations $\boldsymbol{u}=\boldsymbol{G} \boldsymbol{v}$ for a 3-D grid of cells. We propose here a more ambitious task: to include within the geodetic data also the gravity changes and invert for a single source a model for pressure changes and a model for mass changes for the same area, working in a 3-D nonlinear context.

[7] Camacho et al. [2000, 2002, 2007] present an original methodology for gravity inversion searching for an anomalous density distribution model, defined as a 3-D aggregation of $m$ parallelepiped cells that are filled, in a growth process, by means of prescribed positive and/or negative density contrasts. The success of this structural inversion process gave us the idea to use the same approach to model causative bodies with anomalous density for small gravity changes and even causative bodies with anomalous pressure for surface deformation. Here, we present a new methodology for the simultaneous inversion of gravity changes and/ or surface deformation (three components and/or LOS InSAR components) by means of extended bodies with anomalous mass and/or pressure and with free geometry. The inversion approach can be applied in a simultaneous run to several types of data: gravity changes, leveling data, GPS positions, InSAR interferograms, etc.

[8] The Campi Flegrei (Italy) caldera provides a test site for this new method. It is located in an active area where a very large deformation has been observed. We have used terrestrial data for elevation changes (leveling) and gravity and satellite InSAR data for the same period, 1992-2000. The detailed application of this new inversion approach can provide interesting information about the mechanisms that have driven the deformation phenomena, highlighting details about the position and morphology of the causative structures for anomalous mass and pressure.

[9] We present below (1) the new methodology for simultaneous inversion of deformation data and gravity changes by means of extended bodies (pressure and/or density) with free geometry in an elastic medium, (2) simulation tests examples (considering an ellipsoidal pressure body and a parallelepiped mass body), and (3) a test study of gravity, leveling, and InSAR data from Campi Flegrei.

\section{Inversion Approach for Gravity Changes and Deformation by Free Extended Bodies}

\subsection{Model Description}

[10] We assume that surface deformation and gravity changes are due to density and/or pressure changes allocated within extended source structures below the surface. The source approach for data fitting is usually based on point sources or spherical, ellipsoidal (prolate or oblate) extended causative bodies characterized by anomalous density or pressure. For simplicity, we assume that anomalous density or pressure changes are nearly homogeneous within the causative bodies according to some prescribed values. We also assume homogeneous elastic conditions. Our purpose is to model the volume of these anomalous extended bodies in a 3-D context with a free geometry. To do it, we develop a methodology rather similar to the growth algorithm previously used for inversion of structural gravity data [Camacho et al., 2000].

[11] A general description of the geometry of the anomalous bodies can be achieved by partitioning the subsurface volume into a dense 3-D grid of point sources. Therefore the geometrical structures will be described by a dense aggregation of elementary point sources. We approximate the gravity and pressure effects in the surface benchmarks by summing up the effects of some suitable point sources filled with some prescribed values for anomalous density or pressure.

\subsection{System of Nonlinear Equations}

[12] We consider a geodetic network composed of several stations $\left(x_{l}, y_{l}, z_{l}\right), l=1, \ldots, n$, where gravity changes $d g_{i}, i=1$, $\ldots, n_{g}$, and position changes $\left(d x_{j}, d y_{j}, d z_{j}\right), j=1, \ldots, n_{p}$, have been observed, nearly simultaneously, but not necessarily in the same locations. Let us name $\boldsymbol{d}$ the $n_{g}+n_{p}$ vector of observables $d g_{i}, d x_{j}, d y_{j}, d z_{j}$. We will try to model this vector by using $m$ buried point sources, located in $\left(X_{k}, Y_{k}, Z_{k}\right)$, $k=1, \ldots, m$, and characterized by corresponding values for volume $v_{k}$, (positive or negative) incremental pressure $p_{k}$, and (positive or negative) incremental density $\rho_{k}$. We fit the data $\boldsymbol{d}$ as

$$
\boldsymbol{d}=\boldsymbol{d}^{c}+\varepsilon,
$$

where $\boldsymbol{d}^{c}$ represents the $n_{g}+n_{p}$ vector of modeled values $d g_{i}^{c}, d x_{j}^{c}, d y_{j}^{c}$, and $d z_{j}^{c}$ for gravity and position changes, and $\varepsilon$ is the $n_{g}+n_{p}$ vector for residual values coming from inaccuracies in the observation process and also from insufficient model fit. We calculate simultaneously the modeled changes, $d g_{i}^{c}, d x_{j}^{c}, d y_{j}^{c}$, and $d z_{j}^{c}$ by means of simple formulas 
for vertical attraction and deformation effects that are due to additional mass and pressure of several point sources $\left(X_{k}, Y_{k}, Z_{k} ; v_{k}, \rho_{k}, p_{k}\right)$ within an homogeneous elastic halfspace characterized by a shear modulus $\mu$ (given in stress units of pascals $(\mathrm{Pa})$ ) and a Poisson's ratio of $v \cong 0.25$ (dimensionless).

[13] The surface deformation $d x, d y, d z$ that is due to a buried point source is considered mainly as composed by (1) the effects that are due to the incremental pressure $p_{k}$ and expansion radius within the elastic half-space, described by the Mogi model [Masterlark, 2007], and (2) the effects produced by the loading of the additional point mass $v_{k} \times \rho_{k}$ within the elastic half-space, described by the Boussinesq model [Davis and Selvadurai, 1996; Saleh, 2002].

[14] The surface gravity changes $d g$ can be decomposed as follows:

[15] 1. Free-air effect, corresponding to the relocation of the benchmark, is due to elevation changes according a freeair vertical gravity gradient (about $-290 \mu \mathrm{Gal} / \mathrm{m}$ for Campi Flegrei); this effect can be included in the model fit using modeled or observed elevation changes.

[16] 2. Newtonian effects are due to density changes within the original boundaries of the deep bodies.

[17] 3. Newtonian effects are due to mass relocation or change of volume.

[18] 4. Effects are due to mass uplift in the surface corresponding to elevation changes; these effects can be obtained using another vertical gravity gradient, depending on the regional terrain density (similar to the Bouguer correction [Rundle, 1978; Walsh and Rice, 1979; Currenti et al., 2007]). Effects 1 and 4 depend on the surface elevation changes and can be combined by using a combined gravity gradient $F$ (about $-210 \mu \mathrm{Gal} / \mathrm{m}$ ).

[19] 5. Water table effects correspond to very local and shallow perturbations and must be included in the reduction process. Therefore, we will consider reduced data free of these last effects.

[20] 6. Topographical effects are used for the approximate approach of assuming different source depths at each point [Williams and Wadge, 1998; Battaglia and Hill, 2009].

[21] Furthermore, we assume possible common and constant terms $d x_{0}, d y_{0}, d z_{0}$ for the position changes (for instance an unknown change of the leveling origin) and a possible constant term $d g_{0}$ (simplest form of a long-wave component, a global offset value, or a common uncorrected groundwater effect). Then, we adopt the following expressions for the modeled changes:

$$
\begin{array}{r}
d g_{i}^{c}=G \sum_{k=1}^{m} \mathrm{v}_{k} \rho_{k} \frac{z_{i}-Z_{k}}{d_{i k}^{3}}+d g_{o}+F \cdot d z_{i}^{c}, \\
i=1, \ldots, n_{g} \\
d z_{j}^{c}=-\sum_{k=1}^{m} \frac{g_{0}}{4 \pi \mu d_{j k}}\left[2 \cdot(1-v)+\frac{\left(z_{j}-Z_{k}\right)^{2}}{d_{j k}^{2}}\right] \mathrm{v}_{k} \rho_{k} \\
+\sum_{k=1}^{m} \frac{1-v}{4 \pi \mu} \frac{z_{j}-Z_{k}}{d_{j k}^{3}} 3 \mathrm{v}_{k} \mathrm{p}_{k}+d z_{0}, \\
j=1, \ldots, n
\end{array}
$$

$$
\begin{aligned}
d x_{j}^{c}= & -\sum_{k=1}^{m} \frac{g_{0}\left(x_{j}-X_{k}\right)}{4 \pi \mu d_{j k}}\left[\frac{z_{j}-Z_{k}}{d_{j k}^{2}}-\frac{1-2 v}{d_{j k}+z_{j}-Z_{k}}\right] \mathrm{v}_{k} \rho_{k} \\
& +\sum_{k=1}^{m} \frac{1-v}{4 \pi \mu} \frac{x_{j}-X_{k}}{d_{j k}^{3}} 3 \mathrm{v}_{k} \mathrm{p}_{k}+d x_{0},
\end{aligned}
$$

$j=1, \ldots, n$

$$
\begin{aligned}
d y_{j}^{c}= & -\sum_{k=1}^{m} \frac{g_{0}\left(y_{j}-Y_{k}\right)}{4 \pi \mu d_{j k}}\left[\frac{z_{j}-Z_{k}}{d_{j k}^{2}}-\frac{1-2 v}{d_{j k}+z_{j}-Z_{k}}\right] \mathrm{v}_{k} \rho_{k} \\
& +\sum_{k=1}^{m} \frac{1-v}{4 \pi \mu} \frac{y_{j}-Y_{k}}{d_{j k}^{3}} 3 \mathrm{v}_{k} \mathrm{p}_{k}+d y_{0},
\end{aligned}
$$

$j=1, \ldots, n$

where

$$
\begin{gathered}
r_{i k}=\left(\left(x_{i}-X_{k}\right)^{2}+\left(y_{i}-Y_{k}\right)^{2}\right)^{1 / 2} \\
d_{i k}=\left(\left(x_{i}-X_{k}\right)^{2}+\left(y_{i}-Y_{k}\right)^{2}+\left(z_{i}-Z_{k}\right)^{2}\right)^{1 / 2}
\end{gathered}
$$

$G$ is the gravitation constant, $v, \mu$ are elastic parameters (Poisson ratio and shear modulus), and $g_{0}$ is a mean surface gravity value $\left(g_{0} \approx 9.8 \mathrm{Gal}\right)$. By substituting $d z_{i}^{c}$ from equation (3) into equation (2) we get

$$
\begin{aligned}
d g_{i}^{c} & =\sum_{k=1}^{m}\left\{G \frac{z_{i}-Z_{k}}{d_{i k}^{3}}-\frac{g_{0}}{4 \pi \mu} \frac{F}{d_{i k}}\left[2 \cdot(1-v)+\frac{\left(z_{i}-Z_{k}\right)^{2}}{d_{i k}^{2}}\right]\right\} \mathrm{v}_{k} \rho_{k} \\
& +F \sum_{k=1}^{m} \frac{1-v}{4 \pi \mu} \frac{z_{i}-Z_{k}}{d_{i k}^{3}} 3 \mathrm{v}_{k} \mathrm{p}_{k}+d g_{o}+F d z_{0}, \quad i=1, \ldots, n_{g} .
\end{aligned}
$$

System (3)-(6) is constituted by linear equations for $\rho_{k}$ and $p_{k}$, but by a nonlinear relationship with respect to the geometrical parameters (point sources "filled" with nonnull anomalous density or/and nonnull anomalous pressure). Let us observe that we prefer to calculate the free-air and "Bouguer" effects of the elevation changes as proportional to the modeled values $d z_{j}^{c}$, instead of proportional to the observed ones. It allows us to include gravity and elevation changes corresponding to different stations, and it gives better final results.

[22] In the case of InSAR data, deformation $d s$ on the surface points is measured along the radar line of sight (LOS) corresponding to the direction of the satellite antenna. Then, the modeled changes $d s_{i}^{c}$ for the $n$ data points can be written as

$$
\begin{aligned}
& d s_{i}^{c}=d z_{i}^{c} \cos \beta+d x_{i}^{c} \sin \beta \cos \alpha-d y_{i}^{c} \sin \beta \sin \alpha \\
& i=1, \ldots, n
\end{aligned}
$$

where $\alpha, \beta$ are the direction angles (azimuth and incidence) for the antenna pointing direction.

\subsection{Misfit Conditions}

[23] If we assume a Gaussian distribution of the uncertainty, described by a covariance matrix $\boldsymbol{Q}_{\boldsymbol{D}}$ for the gravity and position data $d g_{i}$ and $d x_{j}, d y_{j}, d z_{j}$ (or $d s_{j}$ ), then the minimization condition for residuals $\varepsilon, \varepsilon^{T} \mathbf{Q}_{\mathbf{D}}^{-1} \varepsilon=\min$, leads to the maximum likelihood solution. If we also assume that the data are not correlated, $\boldsymbol{Q}_{\boldsymbol{D}}$ is a diagonal matrix of 


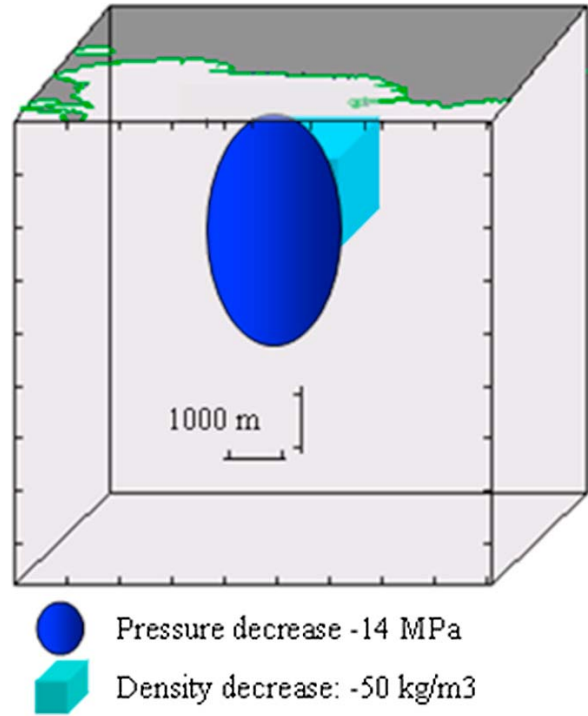

Figure 1. Simulated anomalous bodies for low density (a light blue right parallelepiped) and low pressure (a dark blue vertical ellipsoid). These nonconcentric bodies are assumed below the same zone used for the further application case (Campi Flegrei). Tick marks indicate $1000 \mathrm{~m}$.

estimated variances corresponding to observation of gravity and position changes. Gravity and elevation observations are independent and, then, $\boldsymbol{Q}_{\boldsymbol{D}}$ can be decomposed into two covariance matrices $\boldsymbol{Q}_{\boldsymbol{G}}\left(n_{g} \times n_{g}\right)$ for gravity and $\boldsymbol{Q}_{\boldsymbol{P}}\left(n_{p} \times\right.$ $n_{p}$ ) for position changes. Then the minimization condition for observation residuals can be written as

$$
\varepsilon_{G}^{T} \mathbf{Q}_{G}^{-1} \varepsilon_{G}+\theta \varepsilon_{P}^{T} \mathbf{Q}_{P}^{-1} \varepsilon_{P}=\min ,
$$

where $\varepsilon_{G}$ and $\varepsilon_{P}$ are $n_{g}$ and $n_{p}$ vectors for gravity and elevation residuals and $\theta$ is a weighting factor for the balance between gravity and deformation fits. This factor is introduced to allow a more versatile fit, making it possible to give optional priority to one kind of observable data over the other. Values for $\theta$ can be adopted according to the accuracies of the data sets and considering the approximate equivalence of $1 \mathrm{~cm} \approx 3 \mu \mathrm{Gal}$.

[24] As usually happens for inversion of geophysical data, problems of singularity and instability for the solution can arise because of inadequate data coverage (e.g., usually the number of data points is smaller than the number of unknowns), because of inaccuracy of the data, and because of intrinsic ambiguity of the design problem (in particular, if we assume that positive and negative anomalous density and pressure can be contemporaneously present in the model). A possible approach for solving these problems is to use fuzzy logic [Tiede et al., 2005] based on general properties estimation for the physical environment. A more classical and simple process to avoid the instabilities of the solutions is obtained by means of additional minimization or smoothing conditions for the norm of the solution model as

$$
\mathbf{m}^{T} \mathbf{Q}_{M}^{-1} \mathbf{m}=\min ,
$$

where the model vector $\boldsymbol{m}$ is constituted by the values $\rho_{k}, p_{k}$, $k=1, \ldots, m$, for the cells of the model and $\boldsymbol{Q}_{\boldsymbol{M}}$ is a suitable covariance matrix corresponding to the physical configuration of cells and benchmarks. This matrix provides a balanced model, avoiding very shallow solutions. We use a normalizing diagonal matrix $\boldsymbol{Q}_{\boldsymbol{M}}$ with elements $q_{k}, k=1, \ldots$, $m$, given for volumes $v_{k}$ and distances $d_{j k}$ as

$$
q_{k}=\frac{\mathrm{v}_{K}}{n} \sum_{j=1}^{n} \frac{\left|z_{j}-Z_{k}\right|}{d_{k j}^{3}} .
$$

Condition (9) is a stabilizing term [e.g., Farquharson and Oldenbourg, 1998; Bertete-Aguirre et al., 2002] to control the whole incremental mass and the whole pressure for the bodies (weighting according to matrix $\boldsymbol{Q}_{\boldsymbol{M}}$ ). It prevents very large fictitious values of mass and/or pressure resulting from a rather poorly determined model (for instance, one that is due to the coupling of some positive and negative sources, aligned stations, peripheral sources).

[25] A mixed minimization equation,

$$
S(\mathbf{m})=\varepsilon^{T} \mathbf{Q}_{D}^{-1} \varepsilon+\lambda \mathbf{m}^{T} \mathbf{Q}_{M}^{-1} \mathbf{m}=\min ,
$$

is finally adopted constraining equation (6) for residuals and for model magnitude. $\lambda$ is a factor for selected balance between fitness and smoothness of the model. Low $\lambda$ values produce a very good data fit (even with noise inversion!) but also produce too extended and/or irregular models. Conversely, high $\lambda$ values produce concentrated and smooth models but a poor data fit (even with autocorrelated residuals). The optimal choice is determined by an autocorrelation analysis of the residual values, as that value producing a null (planar) autocorrelation distribution. See Camacho et al. [2007] for more details.

\subsection{Exploration Approach for Solving the System}

[26] The model system, (3)-(6), must be satisfied within the minimization constraint (11). The system constitutes a nonlinear problem of optimization with respect to the geometrical properties. Iterative or explorative methods are mostly used for this purpose [Tarantola, 1987]. Iterative methods (gradient methods) are supported by a long tradition, but they involve starting with a good initial solution. The more versatile explorative methods can be advantageously applied when the model space to be explored is reasonably sized (small number and range of parameters). In this case, random explorative processes (e.g., genetic algorithm or simulated annealing) are mostly adopted. However, taking into account the very large number of degrees of freedom for describing the density and pressure models (as aggregations of thousands of small cells filled with anomalous values), a general exploratory inversion approach, simultaneously for the whole cells, would be ineffective. An alternative approach is to build the anomalous 3-D structures by means of a growth process and then to apply an exploratory approach for each step of the growth process.

[27] In fact, we carry out a step-by-step process of growth of the 3-D models, using an exploratory technique to find a new cell to be filled with density and/or pressure and aggregated to the models. Therefore, for the $k$ th step of the growth process, $k$ cells have been filled with the prescribed anomalous values for pressure and density, giving rise to 

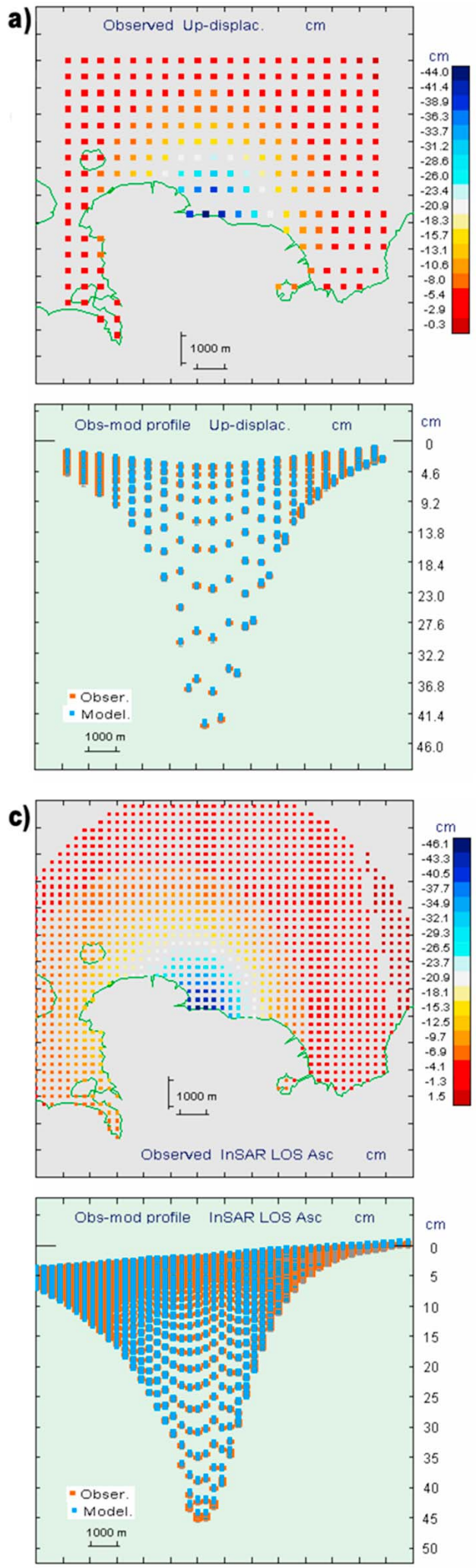
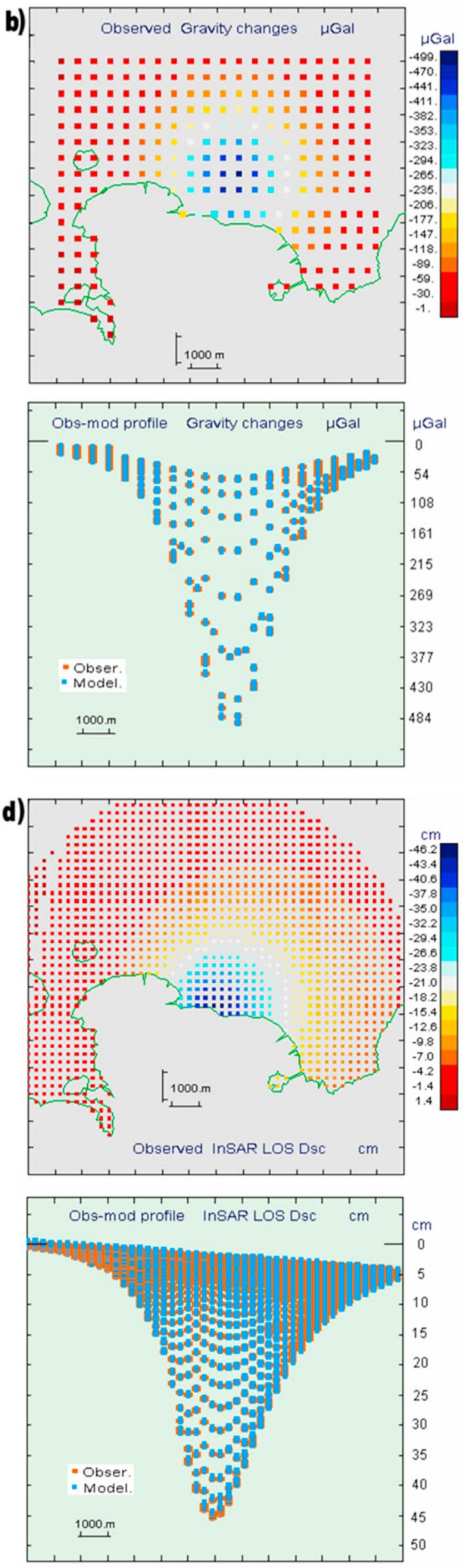

Figure 2. Location of a regular net with step 600 composed of 233 benchmarks on the application area and a regular net of 2656 pixels for InSAR data. Simulated values for the observable fields: (a) vertical deformation, (b) gravity changes, (c) LOS deformation for ascending pass, and (d) LOS deformation for descending pass, for the observation points. Tick marks indicate $1000 \mathrm{~m}$. Blue, modeled values; orange, observed values. 


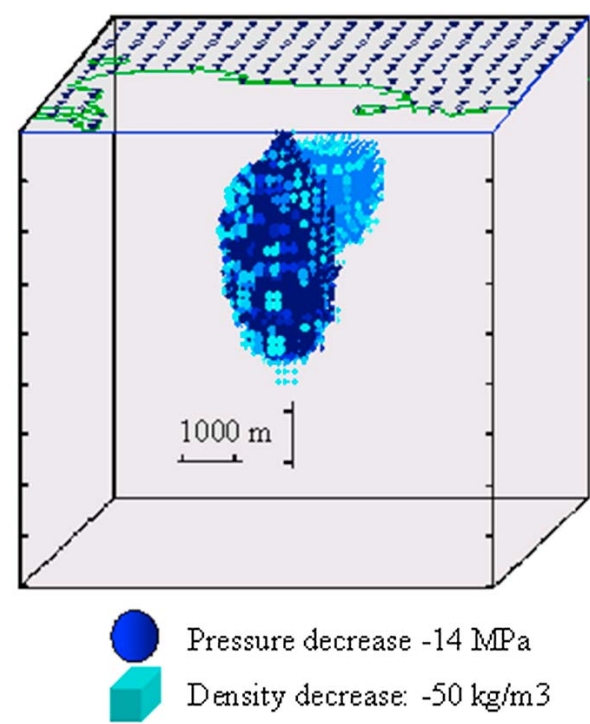

Figure 3. A 3-D view of the modeled anomalous bodies for the simulated test. Dark blue indicates a low-pressure body; light blue indicates a low-density body. This inversion model fits that of Figure 1.

modeled values $\boldsymbol{d}^{c}$. Then for the new $(k+1)$ th step, we try to find and fill a new cell to fit the system:

$$
\begin{gathered}
\boldsymbol{d}=f \boldsymbol{d}^{c}+\varepsilon \\
\varepsilon^{T} \boldsymbol{Q}_{\mathrm{D}}^{-1} \varepsilon+\lambda f^{2} \boldsymbol{m}^{T} \boldsymbol{Q}_{M}^{-1} \boldsymbol{m}=\min ,
\end{gathered}
$$

where $f>1$ is a scale factor to allow for a fit between the anomaly of the provisional (not totally developed) model and the observed anomaly (gravity and position changes). To solve it, we calculate the value $e^{2}=\varepsilon^{T} \boldsymbol{Q}_{\mathrm{D}}^{-1} \varepsilon+\lambda f^{2} \boldsymbol{m}^{T} \boldsymbol{Q}_{\mathrm{M}}^{-1} \boldsymbol{m}$ for the empty cells according to an exploratory technique. In the $(k+1)$ th step we choose, as an optimal cell to be filled, the $j$ th cell, one giving

$$
e_{j}^{2}=\min .
$$

The process continues until we reach a scale factor value $f \cong 1$. As a final result, we arrive nearly automatically at 3-D models described as the aggregation of point sources filled with the prescribed anomalous values for density and pressure. They fit simultaneously the observed values for gravity and position changes well enough and keep a small size for both anomalous models.

[28] Camacho et al. [2000 and 2002] and Gottsmann et al. [2008] give some simulation examples showing the suitability of this 3-D inversion approach as applied to gravity data. Results are quite satisfactory. A certain trend to produce rounded bodies or other distortions is observed for the low-reliability zones (mainly because of the additional condition necessary to solve the underdetermined system; see equation (9)).

\section{Simulation Tests}

[29] To give an idea of the performance of the inversion process, we consider some test simulation examples. They are referred to the same geographical location used for the next application study, the Campi Flegrei caldera (Italy). We consider a set of model parameters obtained previously in this area for another time period [Gottsmann et al., 2006a], which represents an overpressured region geometrically described by a vertical ellipsoid located at a depth (center) of $2900 \mathrm{~m}$ below sea level (bsl), with semiaxes at $2200 \mathrm{~m}$ and $1400 \mathrm{~m}$. The simulated source has a fixed pressure change of $-14 \mathrm{MPa}$ (see Figure 1). In addition, we assume that there is a region, described by a right parallelepiped with sides of 2000 and $4000 \mathrm{~m}$ and centered at a depth of $2000 \mathrm{~m}$ bsl (not far from the ellipsoid), characterized by a uniform density decrease of $-50 \mathrm{~kg} / \mathrm{m}^{3}$ (see Figure 1). The combined effect of both anomalous regions produces surface deformation and gravity changes. Assuming an elastic medium characterized by shear modulus $=10 \mathrm{GPa}$ and Poisson ratio $=0.25$, and assuming a vertical gravity gradient (free-air and Bouguer) of $-220 \mu \mathrm{Gal} / \mathrm{m}$, we can calculate the simulated values for gravity changes and deformation on the surface. We consider the "observed" data set as composed by (1) gravity changes, $d g_{i}$, and vertical changes from leveling (up component), $d z_{i}$, for 233 terrestrial benchmarks corresponding to a nearly regular grid with a step of $600 \mathrm{~m}$ covering the inland area, and (2) synthetic InSAR values of LOS displacement for both ascending and descending orbits, $d s_{i}$, for 2656 simulated pixels according to a grid with a step of $300 \mathrm{~m}$ over the inland area (see Figure 2). We note that data cover only a little bit more than half of the simulated pressure body. We assume as direction angles (incidence angle and azimuth) for the $\operatorname{LOS} \alpha=23^{\circ}, \beta=-13^{\circ}$ for the ascending pass and $\alpha=23^{\circ}, \beta=-167^{\circ}$ for the descending pass. First, we assume no errors in the data. Figure 2 shows the simulated field for the observation points: gravity changes, vertical deformation, and InSAR LOS deformation, for ascending and descending passes.

[30] We apply the previously described inversion methodology to obtain a density-pressure model fitting simultaneously gravity changes and displacement. Assuming a similar relative quality for components of the deformation vector and gravity changes, we choose the homogenization value $\theta$ in equation (8) as corresponding to the vertical gravity gradient, which relates both magnitudes.

[31] Then we take a subsurface partition into 9,609 small cells with mean side step of $90 \mathrm{~m}$. It recovers the significant domain below the survey area. After some trial and error, we choose a $\lambda$ value that allows a sufficient level of fit: about $0.1 \mathrm{~cm}$ for vertical and InSAR data and about $2 \mu \mathrm{Gal}$ for the gravity data. The corresponding inverse model is obtained automatically. Figure 3 shows a three-dimensional view, and Figure 4 shows several horizontal and vertical profiles.

[32] We observe that the fit between simulated and modeled structures is satisfactory. Magnitude, location, depth, and geometry of the modeled structures approach those of the original structure. Some comments can be made.

[33] First, we observe that the inversion approach tends to generate rather rounded bodies. In fact, the ellipsoid is a rounded body, and its corresponding model fits its rounded geometry quite well. In contrast, the original anomalous density body is a prism with sharp vertices. The corresponding inversion structure fits the location, depth, and 
a)

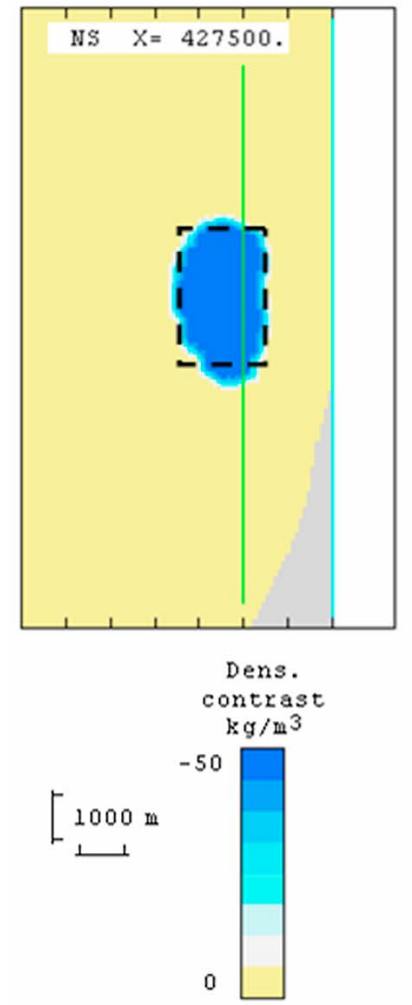

b)
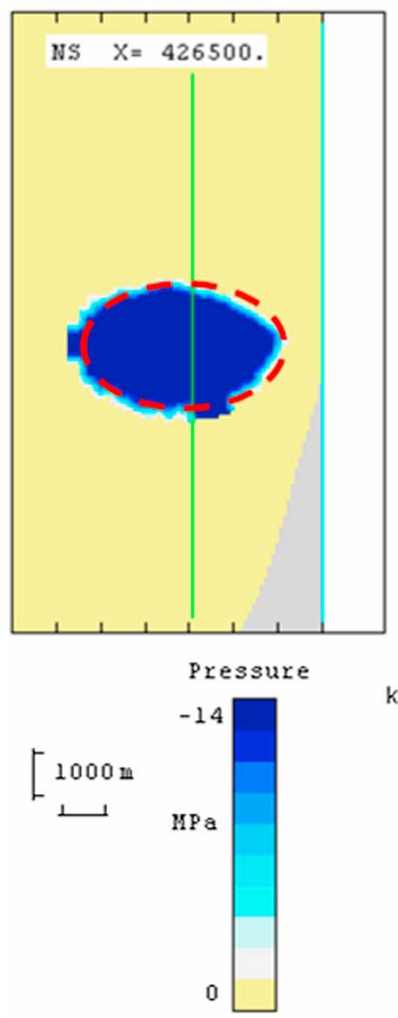
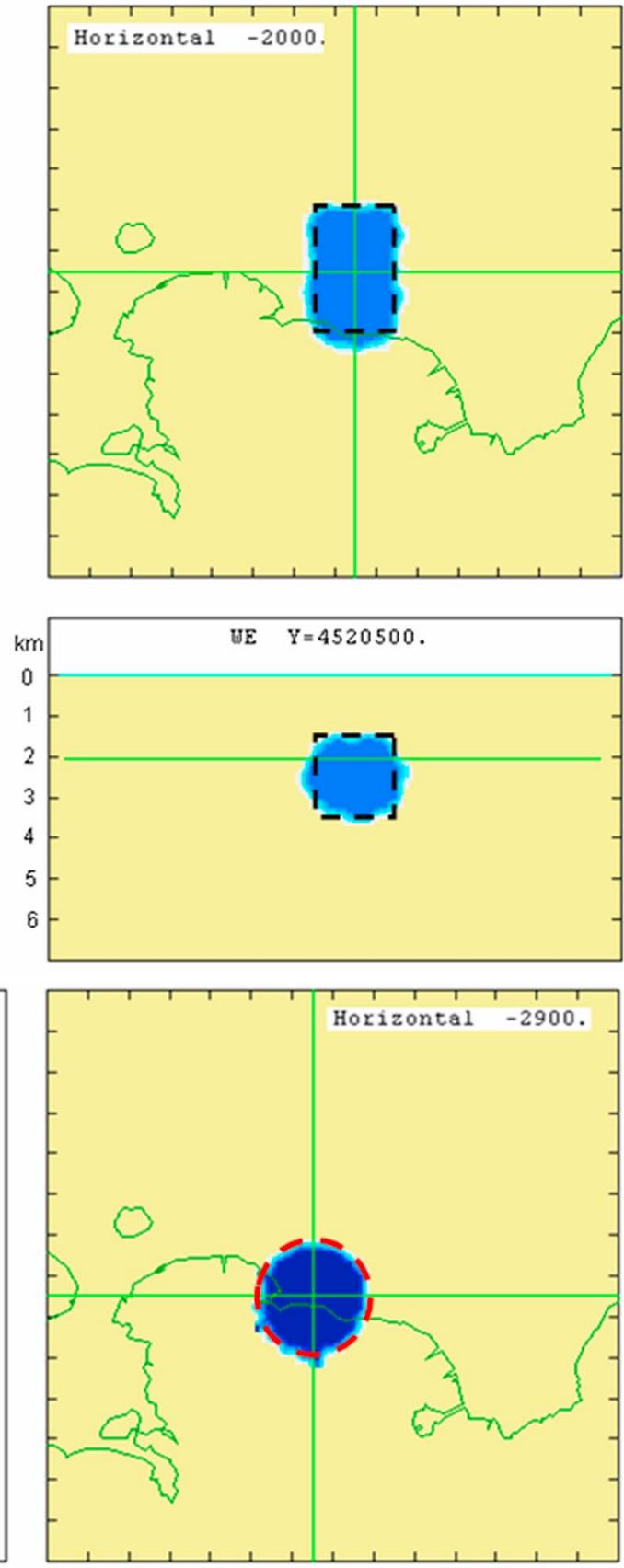

UE $\mathrm{Y}=4519500$.

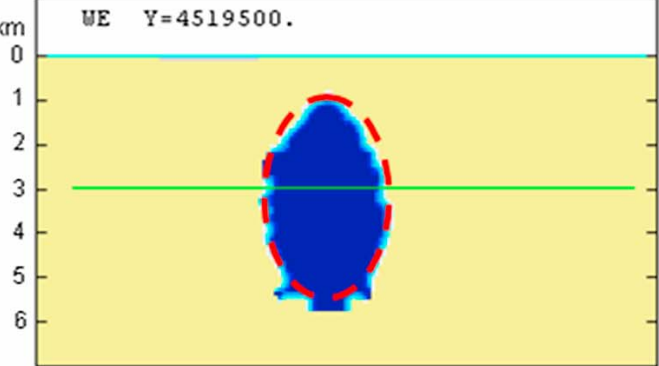

Figure 4. Vertical and horizontal sections of the modeled anomalous bodies for the simulated test: (a) model for density changes and (b) model for pressure changes. Superimposed dotted lines indicate the original simulated bodies. 

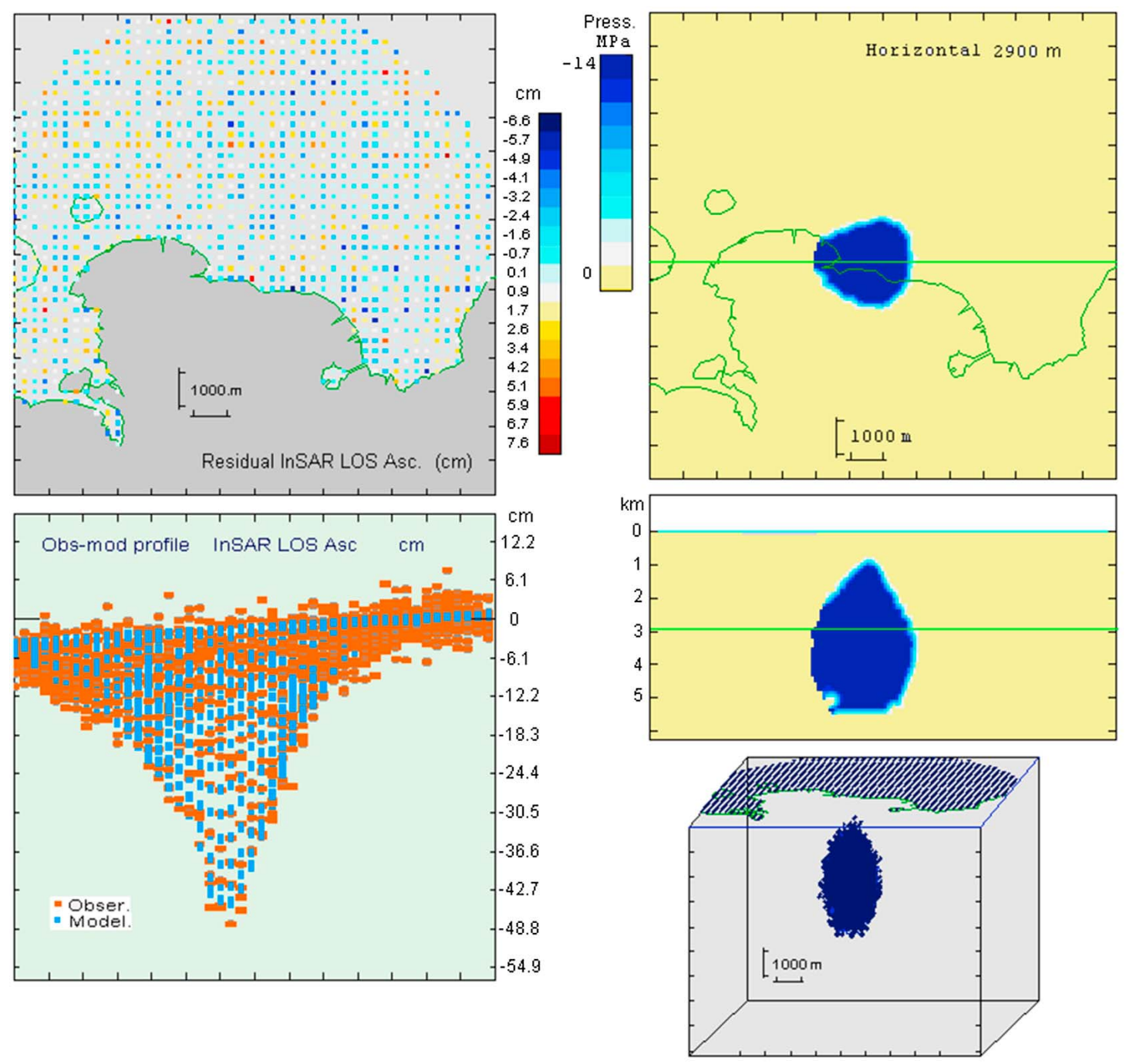

Figure 5. Inversion results corresponding to the simulated model including a simulated noise (with a standard deviation of $2 \mathrm{~cm}$ ) for both components of the LOS InSAR deformation: (a) inversion residuals for ascending LOS, (b) comparison between observed and modeled values, (c) two profiles of the inverse model for anomalous pressure, and (d) a 3-D view of this model.

magnitude, but offers a more rounded geometry (because of the imposed smoothing condition (9)).

[34] Second, the sizes and depth are quite good. However, for the case of the depressurized ellipsoid we observe some expansion in its bottom that exceeds the original contour. It is produced because the bottom of the ellipsoid is too deep with respect to the survey range. Also, for very peripheral or very deep areas in the model, some distortions can be observed. In addition, we must remember that the data cover only a little bit more than a half of the horizontal extension at the surface of the anomalous body.

[35] Now we repeat the inversion process, adding a Gaussian noise to the simulated data obtained from a single ellipsoidal source. For instance, we have included a Gaussian noise with a standard deviation of $2 \mathrm{~cm}$ in both components of LOS InSAR data. It corresponds to about $23 \%$ of the nonperturbed signal. With a no-null noise level, the suitable $\lambda$ value is smaller to keep the fit within the new assumed noise level. The resulting inverse model (Figure 5) is very similar to the former, but presents some slight distortion and involves a smaller size (only about 1\%). With an even higher noise level, the model fits only the correlated signal in the data, and the model becomes even more simplified.

\section{Application: Modeling of Campi Flegrei Unrest}

[36] To show the applicability of our methodology, we apply it to actual data from the caldera of Campi Flegrei (Italy). We use gravity and leveling data as gravity benchmarks and LOS deformation observed by InSAR for ascending and descending passes. All the data correspond to nearly the same time period, 1992-2000. To get a longer overlapping between the data, we consider a somewhat different case: We use change rates, mean annual displacement or gravity changes. 


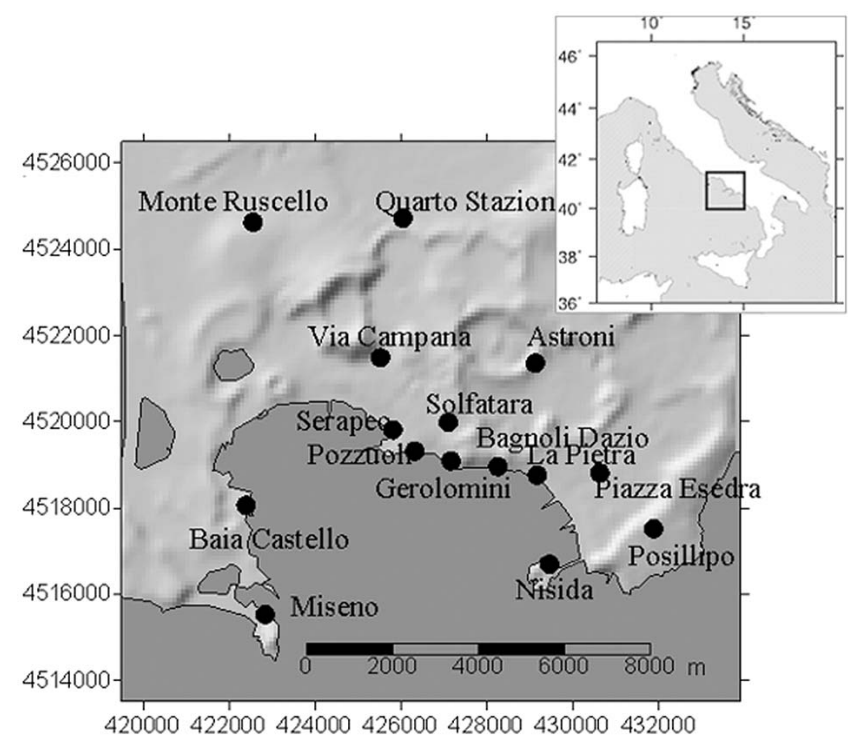

Figure 6. Location of survey benchmarks for repeated gravity and leveling in Campi Flegrei.

\subsection{Campi Flegrei: Geological Setting, Volcanic History, and Previous Geophysical Models}

[37] Campi Flegrei is a caldera complex (Figure 6). Its activity was dominated by two main eruptions that produced widespread ash flow deposits and two collapses, forming two nested calderas [Lirer et al., 1987] of $12 \mathrm{~km}$ [Rosi and Sbrana, 1987; Barberi et al., 1991] and about $8 \mathrm{~km}$ [Lirer et al., 1987; Scandone et al., 1991; Orsi et al., 1992, 1996] in diameter. Postcaldera activity was mainly explosive and produced several vents inside the caldera, most of which aligned in NW-SE and NE-SW directions, highlighting a regional tectonic influence on the volcanic activity $[D i$ Girolamo et al., 1984].

[38] Several geophysical studies have contributed to define the tectonic settings of the area, supporting the hypothesis of the occurrence of a sunken area in the middle of Campi Flegrei [Nunziata and Rapolla, 1981; Cassano and La Torre, 1987; Rapolla et al., 1989; Fedi et al., 1991; Berrino et al., 1998, 2008; Florio et al., 1999; Tramelli et al., 2006]. Campi Flegrei is a site of continual slow vertical movements (Bradyseism). Deformation is centered around Pozzuoli and decreases smoothly away from Pozzuoli, becoming negligible at a distance of about 6-7 km from the town center, just beyond the caldera rim [Corrado et al., 1976; Berrino et al., 1984; Berrino, 1998].

[39] Many authors modeled and interpreted the displacement pattern associated with uplift and deflation and suggested an internal source of volume change located at a depth between 2.7 and $5.4 \mathrm{~km}$ [e.g., Corrado et al., 1976; Berrino et al., 1984; Bonasia et al., 1984; Bianchi et al., 1987; Dvorak and Berrino, 1991; Avallone et al., 1999; Fernández et al., 2001; Lundgren et al., 2001; Bonafede and Ferrari, 2009]. Regarding source(s) controlling the rapid uplift and the slow deflation, some initial studies [e.g., Berrino et al., 1992] supported the existence of a shallow magma reservoir beneath the caldera, while others identified [e.g., Battaglia et al., 2006] the existing hydrothermal sys- tem as a more likely source. The slow deflation, partly considered in this paper, was generally interpreted as longterm pressure decrease in the source that was due to (1) mass loss (perhaps magma drainage) [Berrino et al., 1992], (2) groundwater removal from water saturated deposits that fill the caldera [Dvorak and Berrino, 1991; Berrino, 1994], (3) exhaustion of overpressure in the hydrothermal system [Bonafede and Mazzanti, 1998; Lundgren et al., 2001], or (4) some combination of them. A critical reevaluation of results from previously published models and inverting post-1994 data to infer source parameters for the first time was made by Gottsmann et al. [2006a]. They inverted leveling and tide-gauge data for a spherical point (Mogi model) source, a penny-shaped crack, and finally a prolate spheroid located about $800 \mathrm{~m}$ east of Pozzuoli at a depth of $2.9 \mathrm{~km}$. They inferred a hybrid nature of the source, including both magmatic and hydrothermal components. A shallow (about $3 \mathrm{~km}$ deep) penny-shaped source was instead suggested by Amoruso et al. [2008]. They, for the first time, took into account crustal layering while inverting 1982-1984 leveling, electronic distance measurement (EDM), and gravity data using a uniformly pressurized source, namely small vertical spheroids and a finite horizontal penny-shaped source. They concluded that the source of the 1982-1984 Campi Flegrei (CF) unrest was probably a shallow (about $3 \mathrm{~km}$ deep) penny-shaped magma intrusion fed by a deeper magma chamber. The obtained source overpressure value was a few megapascals.

[40] Repeated gravity measurements, combined with ground deformation data, distinguished two different causative phenomena during uplift and deflation. The 19821984 uplift and the subsequent rapid deflation (until 1987) [Berrino, 1994] may be explained by pressure and mass changes in a deep (3-5 km) magmatic source, probably interacting with a shallow (1-2 km) hydrothermal system, while the slow deflation (since 1988) may be interpreted mainly in terms of the dynamics of the shallow hydrothermal system [e.g., Berrino, 1994; Gottsmann et al., 2003, 2006b, 2006c; Todesco and Berrino, 2005; Battaglia et al., 2006; Amoruso et al., 2008].

[41] In section 4.2 we describe the several geodetic data sets used in our test case.

\subsection{Optical Leveling and Microgravity Data}

[42] The leveling benchmarks we use are only a part of a longer network covering the whole area [Corrado et al., 1976; Berrino et al., 1984; Orsi et al., 1999], referenced to an Istituto Geografico Militare Italiano (IGMI) station located in Naples. The double-run survey meets first-order standards. Uncertainties in elevation differences are less than $\pm 2 \mathrm{~mm} D^{1 / 2}$, where $D$ is the distance along the line between benchmarks [Berrino et al., 1984], and a final uncertainty of the value of $\Delta z$ at each benchmark result is typically less than $1 \mathrm{~cm}$ [Gottsmann et al., 2003].

[43] In the time interval we cover, the gravity network consisted of 15 stations (Figure 6), each one coinciding with benchmarks of the leveling network. It is linked to an absolute gravity station in Naples, outside the volcanic area, chosen as the reference, whose long-term stability is periodically checked through the repetition of the absolute measurements. The absolute gravity measurement in Naples was carried out in 1986 [Berrino, 1995], while a new 


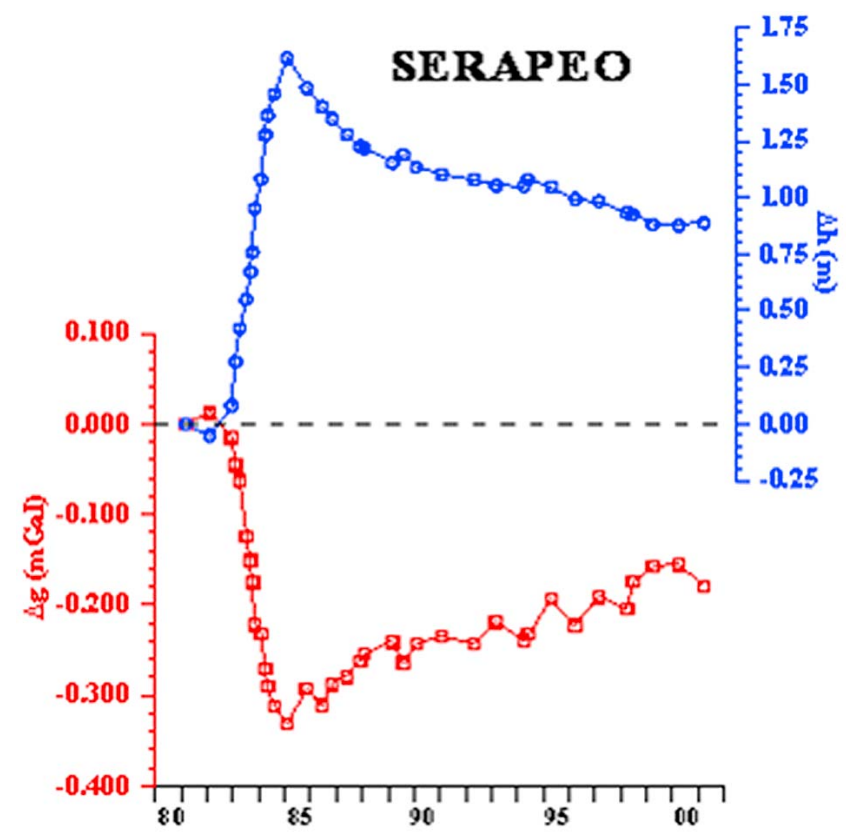

Figure 7. Temporal changes for gravity (red) and elevation (blue) in Serapeo from 1980 to 2000. The vertical dimension of the symbols is representative of the errors. A high correlation is observed between both data, but the elevation values show a more continuous pattern.

absolute gravity station was set up on a selected gravity benchmark at Campi Flegrei (Accademia Aeronautica Pozzuoli) close to the Solfatara crater (Figure 6) [Berrino et al., 1999]. Gravity measurements have been carried out using two LaCoste and Romberg gravimeters. After earthtide, air pressure, and instrumental drift effects were removed from the raw data, the gravity differences between each pair of stations were obtained by a least squares adjustment. The uncertainty of the gravity differences is estimated at less than $10 \mu \mathrm{Gal}$ [Berrino et al., 1984; Berrino, 1994].

[44] Gravity-height data have shown at all times an inverse linear correlation [Berrino et al., 1984; Berrino, 1994]. As an example, in Figure 7 we show the temporal changes for gravity and elevation at the Serapeo station, since it is one of the oldest stations and is close to the area of maximum vertical movements.

[45] We observe that the data for elevation changes show a rather continuous feature in time, but the gravity data contain a higher noise level, showing a larger oscillating feature. Then, instead of the real observed data (the values just observed for 2000 and 1992, independent of the other values), we use some filtered (or interpolated or extrapolated) values. This approach allows us to avoid local or instantaneous perturbations or errors in the data, thus allowing a better definition of the inversion model. In addition, we use a mean deformation rate ( $\mu \mathrm{Gal}$ or centimeters per year) for each station as input data for the inverse approach.

\subsection{Radar Interferometry: Time Series of Differential Interferograms}

[46] The Campi Flegrei caldera has been the target of several previous studies using classical [Avallone et al.,
1999] and advanced differential InSAR methods [Lundgren et al., 2001, Usai, 2003; Berardino et al., 2002; Lanari et al., 2007]. In this study, Small Baseline Subset (SABS) results (linear velocity and displacement time series) were obtained from a set of 165 European Remote Sensing Satellites 1 and 2 (ERS-1 and ERS-2), and 62 ENVISAT SAR data acquired between 1992 and 2008 on ascending (track 129, frame 809) and descending (track 36, frame 2781) orbits [Manconi et al., 2010]. We used a temporal subset of this data set overlapped with the common time span of the leveling and microgravity data. In particular, descending data were limited to the periods 1992-2000 and 1993-2000 for the ascending pass.

[47] In Figure 8, we show the ascending and descending deformation linear rate maps. Both maps show a roughly circular pattern of subsidence (increase in line-of-sight phase change) with maximum average velocities larger than $3 \mathrm{~cm} / \mathrm{yr}$. Through the analysis of the time series, we can distinguish a minor uplift during 1996. However, despite this minor uplift, the linear velocity during the whole period 1992-2000 is negative. Linear ground deformation rate and time series evolution have been extensively validated against independent geodetic techniques [Lanari et al., 2004]. The global precisions of the SBAS results were determined to be $\pm 0.5 \mathrm{~cm}$ and $\pm 0.1 \mathrm{~cm} / \mathrm{yr}$ for the linear ground deformation rate and time series displacement evolution, respectively [Casu et al., 2006].
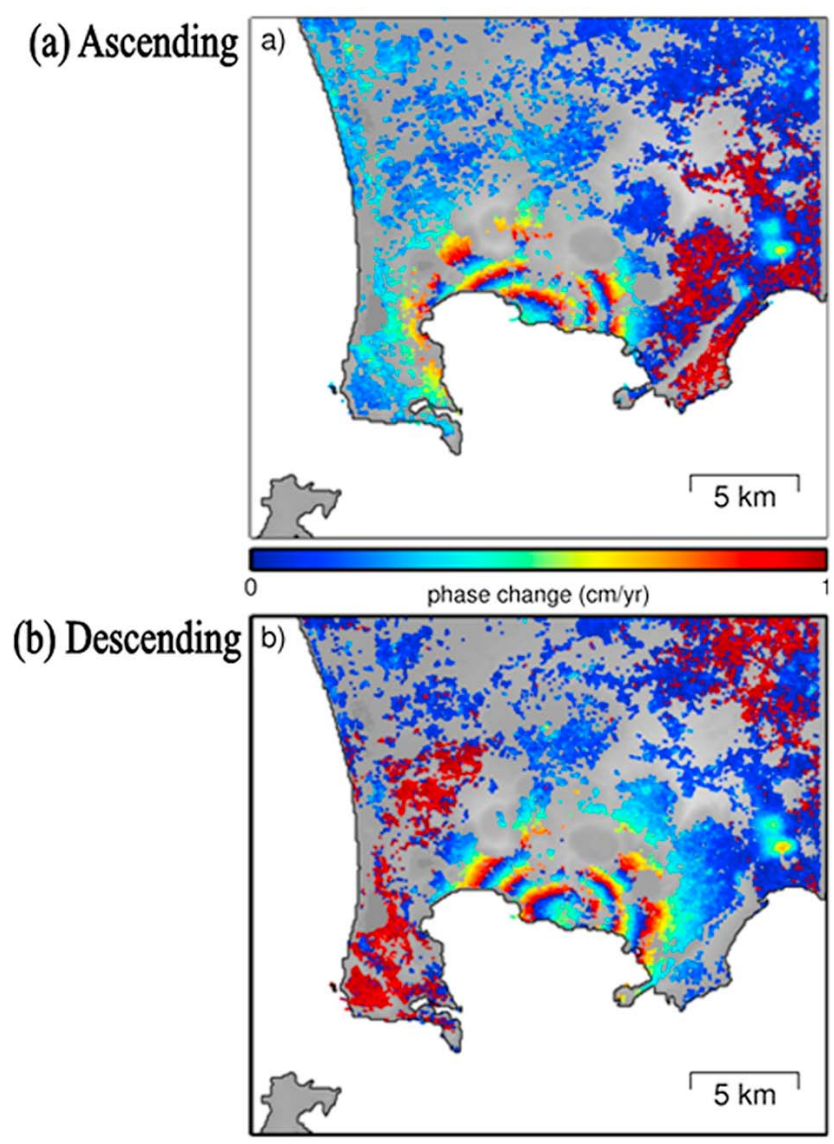

Figure 8. (a) Line-of-sight deformation velocity computed from ascending passes for the period 1993-2000 and (b) line-of-sight deformation velocity computed from descending passes for the period 1992-2000. 

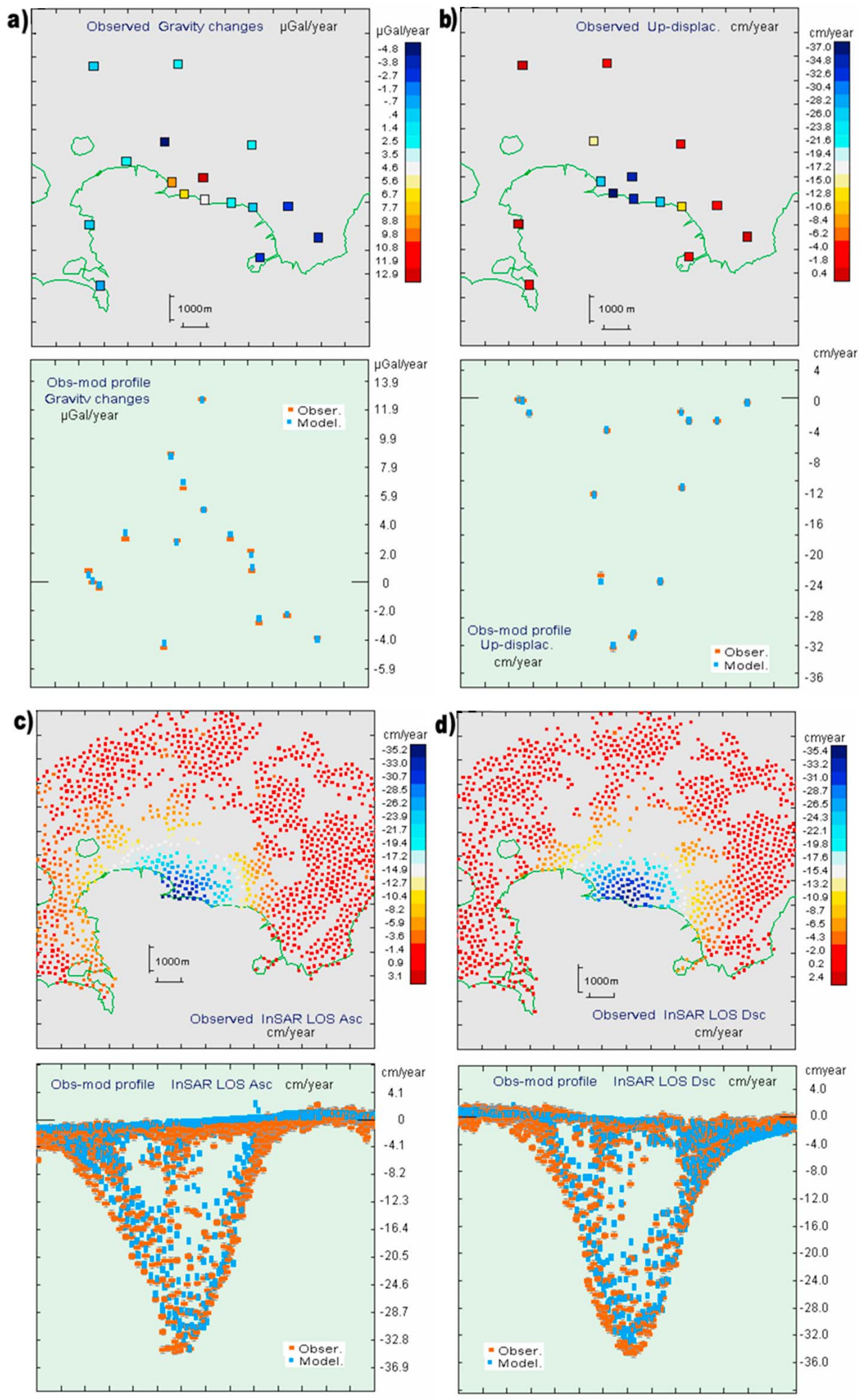

Figure 9. Observed data and observed model fit in Campi Flegrei for 1992-2000 according to the simultaneous inversion approach for anomalous pressure and density 3-D bodies: (a) gravity changes ( $\mu \mathrm{Gal} / \mathrm{yr}$ ), (b) leveling changes ( $\mathrm{mm} / \mathrm{yr})$, (c) LOS deformation for ascending pass ( $\mathrm{mm} / \mathrm{yr})$, and (d) LOS deformation for descending pass ( $\mathrm{mm} / \mathrm{yr}$ ). Tick marks indicate $1000 \mathrm{~m}$. Blue, modeled values; orange, observed values. 


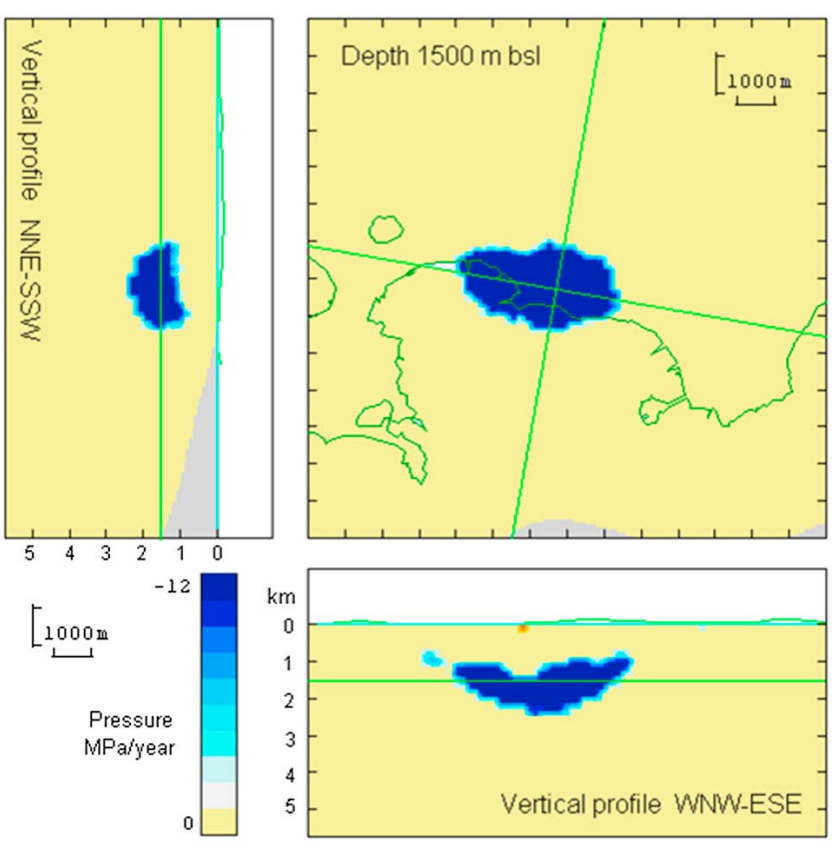

Figure 10. Three cross sections of the 3-D model for depressurization: Horizontal (depth $1500 \mathrm{~m}$ ) and NNESSW and WNW-ESE vertical sections of the under-pressure model across a central position resulting from the simultaneous inversion of the gravity changes, leveling changes, and InSAR data in Campi Flegrei for 1992-2000 assuming an elastic half-space.

\subsection{Simultaneous Modeling of Terrestrial Leveling, Gravity Changes, and InSAR (LOS) Deformation, 1992-2000}

[48] The input data are as follows:

[49] 1. The terrestrial data set in terms of linear deformation velocity includes 15 benchmarks with coordinates $(x, y, z)$, gravity change rates $d g$, and elevation change rates $d z$ for the period 1992-2000. In this time interval the geodetic changes offers a nearly stable pattern: increasing gravity, decreasing elevation (see Figure 7).

[50] 2. Direct inversion of the total InSAR data (about 15,000 points) is rather tedious. For a faster process we select pixels separated by a distance larger than, for instance, $300 \mathrm{~m}$. It produces two subsets, each with approximately 1330 data points.

[51] We apply the new inversion methodology to the combined subsampled data set (about 2670 data points) with both ascending and descending data and the terrestrial gravity and elevation, using all the data simultaneously.

[52] Figure 9 shows the distribution and magnitude of the observed changes in elevation $d z$, gravity $d g$, and ascending and descending LOSs $d s$. This heterogeneous data set constitutes the input values that enter into the inversion approach. A suitable relative weighting for the different types of data is necessary to carry out a simultaneous fit. Leveling data have a good confidence level (better than $1 \mathrm{~cm}$ ), and their temporal evolution is quite stable (e.g., Figure 7). Gravity data also have a good confidence level (better than $10 \mu \mathrm{Gal}$ ), but their temporal evolution seems more noisy (Figure 7). For the InSAR data, we have a rather good accuracy level (assumed to be $\pm 0.5 \mathrm{~cm}$ and $\pm 0.1 \mathrm{~cm} / \mathrm{yr}$ ). In line with these considerations, we assume a similar relative weighting factor for our several types of data (gravity, leveling, and InSAR). Clearly, the modeling process is going to be conditioned by these weighting criteria.

[53] The assumed values for the elastic parameters are Poisson ratio $=0.25$ and shear modulus $=10 \mathrm{GPa}$ [Gottsmann et al., 2006a]. The assumed gravity gradient used is $-220 \mu \mathrm{Gal} / \mathrm{m}$. It corresponds to a free-air value of $-290 \mu \mathrm{Gal} / \mathrm{m}$ [Berrino et al., 1984] and a value $70 \mu \mathrm{Gal} / \mathrm{m}$ for the Bouguer correction for Campi Flegrei, resulting from the analyses carried out by Berrino et al. [1992].

[54] To obtain the inverse models we consider a 3-D partition of the local subsurface volume into 14,500 elemental point sources (located at the center of the cells with sides of about $120 \mathrm{~m}$ ). Using this distribution of "empty" elements, the inversion approach produces the models for pressure and density as defined by the aggregation of filled point sources according to the prescribed extreme values for anomalous density and pressure. After some trials, we select the extreme values $\pm 20 \mathrm{~kg} / \mathrm{m}^{3}$ and $\pm 10 \mathrm{MPa}$ as a suitable contrast to obtain extended anomalous bodies. Suitable values for parameters $\theta$ and $\lambda$ were also chosen taking into account the assumed accuracy of the data (gravity uncertainties smaller than $\pm 10 \mu \mathrm{Gal}$, leveling uncertainties smaller than $\pm 1 \mathrm{~cm}$, and LOS error values of the order of about $\pm 1 \mathrm{~cm})$ and, after some simple trials, looking to obtain compact source bodies and a good fit to the correlated signal in the data. In this step, the inverse process works automatically, and produces a combined model and final residuals. Figure 9 shows the fit between observed and modeled values from the global simultaneous fit. The standard deviation of the inversion residuals is $0.2 \mathrm{~cm} / \mathrm{yr}$ for the elevation changes, $0.6 \mu \mathrm{Gal} / \mathrm{yr}$ for the gravity changes, and about $1.1 \mathrm{~cm} / \mathrm{yr}$ for the LOS values. Figure 10 shows some additional views of the inversion residuals for the case of the ascending LOS component.

[55] The first main result is that the process does not produce any significant region for anomalous positive or negative density. The resulting anomalous model for density changes consists of only a very few filled cells located close to the surface below some benchmarks, which correspond to very local effects. There is no extended body for gravity changes.

[56] The anomalous 3-D depressurized model (Figure 11) shows a clear structure located below Pozzuoli at a mean depth of about $1500 \mathrm{~m}$ bsl. The vertical profiles in Figure 11 suggest a "partially filled parabolic glass" shape along a WNW-ESE course, with a less-developed similar shape along the orthogonal course. The picture also suggests some small tracks from the main body toward the surface.

\section{Summary and Conclusions}

[57] From a methodological point of view, this paper offers a new and simple methodology for carrying out the simultaneous inversion of data for geodetic changes (gravity, leveling, GPS values, InSAR interferograms), assuming that they correspond to changes in density and lithostatic pressure within extended subsurface volumes and within a homogeneous elastic medium. The method allows us to obtain, by means of a nearly automatic approach, constraints about the 
(a)

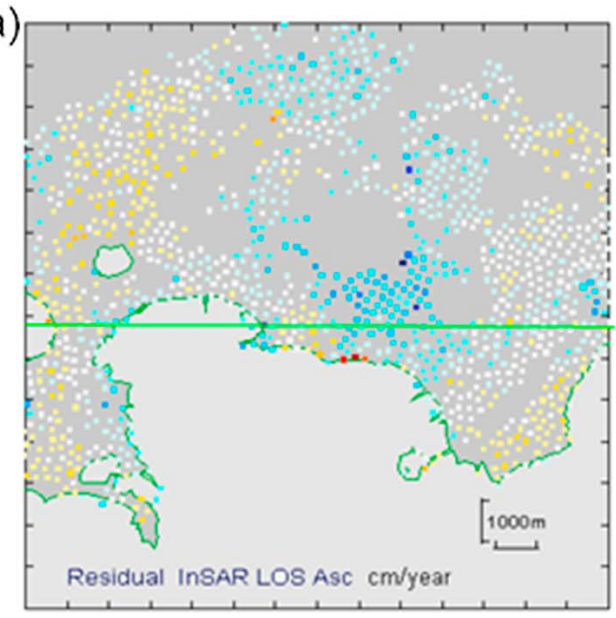

(b)

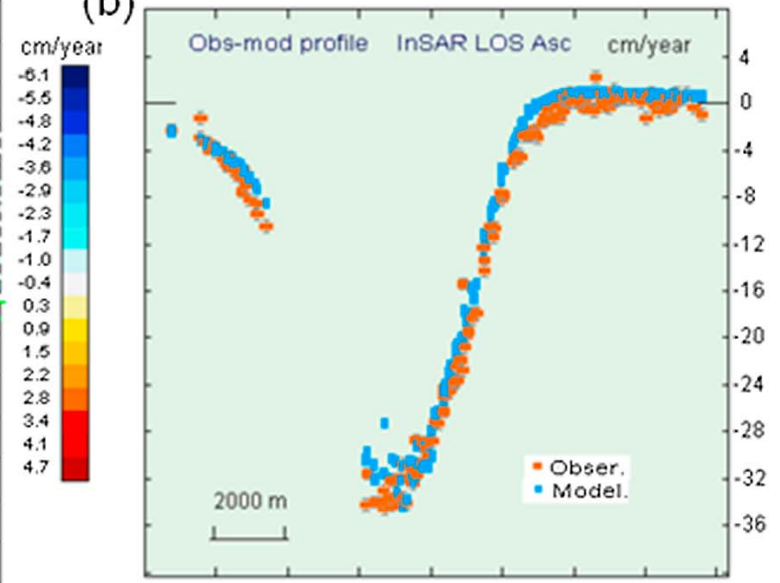

Figure 11. Some additional views of the LOS ascending data fit: (a) residual map and (b) WE central profile for observed-modeled comparison.

location, size, and shape of the source structures as a 3-D distributed source with free geometry. This methodology could be applied in different active areas, e.g., volcanic sites and sites with hydrologic phenomena, using different combinations of observations (for instance, only InSAR data, InSAR plus gravity, leveling plus gravity). The simulation tests show a good modeling approach, especially for sources with smooth shapes. Results could be particularly interesting when compared with general structural models [e.g., Battaglia and Vasco, 2006].This new methodology has been also applied to model leveling, gravity, and InSAR data for Campi Flegrei obtained for the time period 1992-2000.

[58] In this application case, the anomalous mass model obtained from a joint inversion of gravity and leveling changes is nearly empty. There is no anomalous mass below the central area. Only some very shallow (depth about $200 \mathrm{~m}$ ) and small anomalous (positive and negative) masses are adjusted close to some benchmarks, as corresponding to local effects. It suggests that mass changes are not detected below the main deformation area. The gravity changes observed in the benchmarks of the main deformation area can be fully interpreted as produced by freeair and Bouguer effects of the uplift (according the assumed gravity gradient). We can conclude that the phenomena below the central area do not involve input or output of significant mass (magma or fluids).

[59] The absence of a significant mass change would imply no temporal variability of the fluids in the source region. It might be consistent with an exponential decay of fluid pore pressures during the analyzed slowdown subsidence phase (post-1987), following the rapid uplift phases (1982-1984) during which the high-pore-pressure conditions were established. A physical mechanism that could reconcile these observations could be a long-lasting transient pulse of pore-pressure diffusion confined to the caldera filled material, which does not necessarily imply a mass transfer process (fluids in and out) in the hydrothermal system [Talwani and Acree, 1984]. However, the absence of mass change does not preclude high-pore-pressure conditions from producing fluid flow at the more permeable, shallow, hydrothermal system levels, as suggested by the geochemical variation of volatile discharge at Solfatara [Todesco and Berrino, 2005]. Indeed, local fluid flow could explain few very shallow mass change sources required to fit some benchmarks.

[60] All deformation data (terrestrial, ascending, and descending InSAR) provide a similar low-pressure structure located at a shallow depth (about $1500 \mathrm{~m}$ ) below the survey area. The shape of that structure is nearly filling in the bottom of a parabolic cup with the same additional filling in the walls (Figure 9). We do not detect signs of the deep magmatic source for this period. Some main WNW-ESE elongation is detected (about $\mathrm{N} 100^{\circ} \mathrm{E}$ ). The parabolic cup is super imposable to the shape in depth of some structure, namely the inner caldera edge, as depicted by a $2.5-\mathrm{D}$ inversion of on-land and offshore gravity data [Berrino et al., 2008]. Moreover, its bottom corresponds to the depth of the bottom of the inner caldera (between 2 and $2.5 \mathrm{~km}$ ). The modeled structure fits well the polygenic body inside the modeled caldera (see Profiles 2 and 13, respectively, $\mathrm{W}-\mathrm{E}$ and NW-SE crossing the center of the caldera by Berrino et al. [2008]). We interpret it as corresponding to the dynamics of the shallow (depth $1-2 \mathrm{~km}$ ) hydrothermal system, as previously suggested by several authors [e.g., Gottsmann et al., 2003, 2006b; Battaglia et al., 2006]. The hydrothermal system is confined to the filling caldera materials and is limited by the inner caldera structure.

[61] Acknowledgments. This research has been supported by Spanish MICINN projects PEL2G (CGL2008-06426-C01-01/BTE) and GEOSIR (AYA2010-17448). It has been also partially done in the framework of the Moncloa Campus of International Excellence (UCM-UPM, CSIC). Pablo J. González was partly supported by a UCM predoctoral research fellowship and an Ontario Early Researcher Award and the NSERC and Aon Benfield/ ICLR IRC in Earthquake Hazard Assessment at the Department of Earth Sciences of UWO. We thank IREA, Naples, and Pietro Tizzani for kindly providing the InSAR deformation data. The authors are also very grateful to C. Del Gaudio (INGV-OV), who provided the 1988 leveling data. Detailed reviews and suggestions from M. Battaglia and another anonymous reviewer improved the manuscript.

\section{References}

Amoruso, A., L. Crescentini, and G. Berrino (2008), Simultaneous inversion of deformation and gravity changes in a horizontally layered half- 
space: Evidences for magma intrusion during the 1982-1984 unrest at Campi Flegrei caldera (Italy), Earth Planet. Sci. Lett., 272, 181-188, doi:10.1016/j.epsl.2008.04.040.

Avallone, A., A. Zollo, P. Briole, C. Delacourt, and F. Beauducel (1999), Subsidence of Campi Flegrei (Italy) detected by SAR interferometry, Geophys. Res. Lett., 26, 2303-2306, doi:10.1029/1999GL900497.

Barberi, F., E. Cassano, P. La Torre, and A. Sbrana (1991), Structural evolution of Campi Flegrei caldera in light of volcanological and geophysical data, J. Volcanol. Geotherm. Res., 48, 33-49, doi:10.1016/0377-0273(91) 90031-T.

Battaglia, M., and D. P. Hill (2009), Analytical modeling of gravity changes and crustal deformation at volcanoes: The Long Valley caldera, California, case study, Tectonophysics, 471, 45-57, doi:10.1016/j.tecto. 2008.09.040.

Battaglia, M., and D. W. Vasco (2006), The search for magma reservoirs in Long Valley caldera: Single versus distributed sources, Geol. Soc. Spec. Publ., 269, 173-180.

Battaglia, M., F. Obrizzo, F. Pingue, and G. De Natale (2006), Evidence for fluid migration as the source of deformation at Campi Flegrei caldera (Italy), Geophys. Res. Lett., 33, L01307, doi:10.1029/2005GL024904.

Battaglia, M., J. Gottsmann, D. Carbone, and J. Fernández (2008), 4D volcano gravimetry, Geophysics, 73(6), WA3-WA18, doi:10.1190/1.2977792.

Berardino, P., F. Casu, G. Fornaro, R. Lanari, M. Manunta, A. Pepe, and E. Sansosti (2002), A new algorithm for surface deformation monitoring based on small baseline differential SAR interferograms, IEEE Trans. Geosci. Remote Sens., 40(11), 2375-2383, doi:10.1109/ TGRS.2002.803792

Berrino, G. (1994), Gravity changes induced by height-mass variations at the Campi Flegrei caldera, J. Volcanol. Geotherm. Res., 61, 293-309, doi:10.1016/0377-0273(94)90010-8.

Berrino, G. (1995), Absolute gravimetry and gradiometry on active volcanoes of southern Italy. Boll. Geofis. Teor. Appl., XXXVII(146), 131-144.

Berrino, G. (1998), Detection of vertical ground movements by sea-level changes in the Neapolitan volcanoes, Tectonophysics, 294, 323-332, doi:10.1016/S0040-1951(98)00109-7.

Berrino, G., G. Corrado, G. Luongo, and B. Toro (1984), Ground deformation and gravity changes accompanying the 1982 Pozzuoli Uplift, Bull. Volcanol., 47(2), 187-200, doi:10.1007/BF01961548.

Berrino, G., H. Rymer, G. C. Brown, and G. Corrado (1992), Gravityheight correlations for unrest calderas, J. Volcanol. Geotherm. Res., 53 11-26, doi:10.1016/0377-0273(92)90071-K.

Berrino, G., G. Corrado, and U. Riccardi (1998), Sea gravity data in the Gulf of Naples: A contribution to delineating the structural pattern of the Vesuvian area, J. Volcanol. Geotherm. Res., 82, 139-150, doi:10.1016/S0377-0273(97)00061-9.

Berrino, G., G. Cerutti, G. Corrado, P. De Maria, and U. Riccardi (1999), Gravity studies on active Italian volcanoes: A comparison between absolute and relative gravimetry, Boll. Geofis. Teor. Appl., 40, 497-510.

Berrino, G., G. Corrado, and U. Riccardi (2008), Sea gravity data in the Gulf of Naples: A contribution to delineating the Phlegraean Volcanic District, J. Volcanol. Geotherm. Res., 175, 241-252, doi:10.1016/j. jvolgeores.2008.03.007.

Bertete-Aguirre, H., E. Cherkaev, and M. Oristaglio (2002), Non-smooth gravity problem with total variation penalization functional, Geophys. J. Int., 149, 499-507, doi:10.1046/j.1365-246X.2002.01664.x.

Bianchi, R., A. Corradini, C. Federico, G. Giberti, P. Lanciano, J. P. Pozzi, G. Sartoris, and R. Scandone (1987), Modeling of surface deformation in volcanic areas: The 1970-1972 and 1982-1984 crises at Campi Flegrei, Italy, J. Volcanol. Geotherm. Res., 92(14), 139-150.

Bonafede, M., and C. Ferrari (2009), Analytical models of deformation and residual gravity changes due to a Mogi source in a viscoelastic medium, Tectonophysics, 471, 4-13, doi:10.1016/j.tecto.2008.10.006.

Bonafede, M., and M. Mazzanti (1998), Modeling gravity variations consistent with ground deformation in the Campi Flegrei caldera (Italy), J. Volcanol. Geotherm. Res., 81, 137-157, doi:10.1016/ S0377-0273(97)00071-1.

Bonasia, V., F. Pingue, and R. Scarpa (1984), A fluid-filled fracture as possible mechanism of ground deformation at Phlegraean Fields, Italy, Bull. Volcanol., 47(2), 313-320, doi:10.1007/BF01961562.

Camacho, A. G., F. G. Montesinos, and R. Vieira (2000), A 3-D gravity inversion by means of growing bodies, Geophysics, 65(1), 95-101, doi:10.1190/1.1444729.

Camacho, A. G., F. G. Montesinos, and R. Vieira (2002), A 3-D gravity inversion tool based on exploration of model possibilities, Comput. Geosci., 28, 191-204, doi:10.1016/S0098-3004(01)00039-5.

Camacho, A. G., J. C. Nunes, E. Ortiz, Z. França, and R. Vieira (2007), Gravimetric determination of an intrusive complex under the Island of Faial (Azores): Some methodological improvements, Geophys. J. Int., 171, 478-494, doi:10.1111/j.1365-246X.2007.03539.x.
Cassano, E., and P. La Torre (1987), Geophysics, in Phlegrean Fields, Quad. Ric. Sci. CNR, edited by R. Santacroce, pp. 103-133.

Casu, F., M. Manzo, and R. Lanari (2006), A quantitative assessment of the SBAS algorithm performance for surface deformation retrieval from DInSAR data, Remote Sens. Environ., 102, 195-210, doi:10.1016/j. rse.2006.01.023.

Charco, M., J. Fernández, F. Luzón, and J. B. Rundle (2006), On the relative importance of self-gravitation and elasticity in modeling volcanic ground deformation and gravity changes, J. Geophys. Res., 111, B03404, doi:10.1029/2005JB003754

Charco, M., J. Fernández, F. Luzón, K. F. Tiampo, and J. B. Rundle (2007), Some insights into topographic, elastic a self-gravitation interaction in modelling ground deformation and gravity changes in active volcanic areas, Pure Appl. Geophys., 164, 865-878, doi:10.1007/ s00024-004-0190-y.

Corrado, G., I. Guerra, A. Lo Bascio, G. Luongo, and R. Rampoldi (1976), Inflation and microearthquake activity of Phlegraean Fields, Italy, Bull. Volcanol., 40(3), 1-20.

Currenti, G., C. Del Negro, and G. Ganci (2007), Modelling of ground deformation and gravity fields using finite element method: An application to Etna volcano, Geophys. J. Int., 169, 775-786, doi:10.1111/j.1365246X.2007.03380.x.

Davis, R. O., and A. P. S. Selvadurai (1996), Elasticity and Geomechanics, 201 pp., Cambridge Univ. Press, Cambridge, U. K.

Di Girolamo, P., M. Ghiara, L. Lirer, R. Munno, G. Rolandi, and D. Stanzione (1984), Vulcanologia e Petrologia dei Campi Flegrei, Boll. Soc. Geol. Ital., 103, 349-413.

Dvorak, J., and G. Berrino (1991), Recent ground movement and vertical ground movement in Campi Flegrei caldera, southern Italy: Comparison of precursory events to the A.D. 1538 eruption of Monte Nuovo and of activity since 1968, J. Volcanol. Geotherm. Res., 96, 2309-2323.

Eggers, A. (1987), Residual gravity changes and eruption magnitudes, J. Volcanol. Geotherm. Res., 33, 201-216, doi:10.1016/0377-0273(87) 90062-X.

Farquharson, C. G., and D. W. Oldenbourg (1998), Non-linear inversion using general measures of data misfit and model structure, Geophys. J. Int., 134, 213-227, doi:10.1046/j.1365-246x.1998.00555.x.

Fedi, M., C. Nunziata, and A. Rapolla (1991), The Campania-Campi Flegrei area: A contribution to discern the best structural model from gravity interpretation, J. Volcanol. Geotherm. Res., 48, 51-59, doi:10.1016/ 0377-0273(91)90032-U.

Fernández, J., and J. Rundle (1994a), Gravity changes and deformation due to a magmatic intrusion in a two-layered crustal model, J. Geophys. Res. 99, 2737-2746, doi:10.1029/93JB02449.

Fernández, J., and J. Rundle (1994b), FORTRAN program to compute displacement, potential and gravity changes due to a magma intrusion in a multilayered Earth model, Comput. Geosci., 20, 461-510, doi:10.1016/ 0098-3004(94)90079-5.

Fernández, J., K. F. Tiampo, and J. B. Rundle (2001), Viscoelastic displacement and gravity changes due to point magmatic intrusion in a gravitational layered solid earth, Geophys. J. Int., 146, 155-170, doi:10.1046/j.0956-540x.2001.01450.x.

Florio, G., M. Fedi, F. Cella, and A. Rapolla (1999), The Campanian Plain and Phlegrean Fields: Structural setting from potential field data, J. Volcanol. Geotherm. Res., 91, 361-379, doi:10.1016/S0377-0273(99) 00044-X.

Gabriel, A. K., R. M. Goldstein, and H. A. Zebker (1989), Mapping small elevation changes over large areas: Differential radar interferometry, J. Geophys. Res., 94, 9183-9191, doi:10.1029/JB094iB07p09183.

Gottsmann, J., and M. Battaglia (2008), Deciphering causes of unrest at explosive collapse calderas: Recent advances and future challenges of joint time-lapse gravimetric and ground deformation studies, in Caldera Volcanism. Analysis, Modeling and Response, edited by J. Gottsmann and J. Marti, pp. 417-446, Elsevier, New York, doi:10.1016/S1871644X(07)00012-5.

Gottsmann, J., G. Berrino, H. Rymer, and G. William-Jones (2003), Hazard assessment during caldera unrest at the Campi Flegrei, Italy: A contribution from gravity-height gradients, Earth Planet. Sci. Lett., 211 295-309, doi:10.1016/S0012-821X(03)00225-5.

Gottsmann, J., H. Rymer, and G. Berrino (2006a), Unrest at the Campi Flegrei caldera (Italy): A critical evaluation of source parameters from geodetic data inversion, J. Volcanol. Geotherm. Res., 150, 132-145, doi:10.1016/j.jvolgeores.2005.07.002

Gottsmann, J., A. Folch, and H. Rymer (2006b), Unrest at Campi Flegrei: A contribution to the magmatic versus hydrothermal debate from inverse and finite element modeling, J. Geophys. Res., 111, B07203, doi:10.1029/2005JB003745.

Gottsmann, J., A. G. Camacho, K. F. Tiampo, and J. Fernández (2006c), Spatiotemporal variations in vertical gravity gradients at the Campi Fle- 
grei caldera (Italy): A case for source multiplicity during unrest?, Geophys. J. Int., 167, 1089-1096, doi:10.1111/j.1365-246X.2006.03157.x.

Gottsmann, J., A. G. Camacho, J. Marti, L. Wooller, J. Fernández, A. Garcia, and H. Rymer (2008), Shallow structure beneath the Central Volcanic Complex of Tenerife from new gravity data: Implications for its evolution and recent reactivation, Phys. Earth Planet. Inter., 168 , 212-230, doi:10.1016/j.pepi.2008.06.020.

Lanari, R., P. Berardino, S. Borgström, C. Del Gaudio, P. De Martino, G. Fornaro, S. Guarino, G. P. Ricciardi, E. Sansosti, and P. Lundgren (2004), The use of IFSAR and classical geodetic techniques for caldera unrest episodes: Application to the Campi Flegrei uplift event of 2000, J. Volcanol. Geotherm. Res., 133, 247-260, doi:10.1016/ S0377-0273(03)00401-3.

Lanari, R., F. Casu, M. Manzo, G. Zeni, P. Berardino, M. Manunta, and A. Pepe (2007), An overview of the small baseline subset algorithm: A DInSAR technique for surface deformation analysis, Pure Appl. Geophys., 164, 637-661, doi:10.1007/s00024-007-0192-9.

Lirer, L., G. Luongo, and R. Scandone (1987), On the volcanological evolution of Campi Flegrei, Eos Trans. AGU, 68, 226.

Lundgren, P., S. Usai, E. Sansosti, R. Lanari, M. Tesauro, G. Fornaro, and P. Berardino (2001), Modeling surface deformation observed with synthetic aperture radar interferometry at Campi Flegrei caldera, J. Geophys. Res., 106, 19,355-19,366, doi:10.1029/2001JB000194.

Manconi, A., T. R. Walter, M. Manzo, G. Zeni, P. Tizzani, E. Sansosti, and R. Lanari (2010), On the effects of 3-D mechanical heterogeneities at Campi Flegrei caldera, southern Italy, J. Geophys. Res., 115, B08405, doi:10.1029/2009JB007099.

Masterlark, T. (2007), Magma intrusion and deformation predictions: Sensitivities to the Mogi assumptions, J. Geophys. Res., 112 , B06419, doi:10.1029/2006JB004860.

Nunziata, C., and A. Rapolla (1981), Interpretation of gravity and magnetic data in the Phlegrean Fields geothermal area, Naples, Italy, J. Volcanol. Geotherm. Res., 10(1-3), 209-225, doi:10.1016/0377-0273(81)90063-9.

Orsi, G., M. D'Antonio, S. de Vita, and G. Gallo (1992), The neapolitan yellow tuff, a large magnitude trachytic phreatoplinian eruption: Eruptive dynamics, magma withdrawal and caldera collapse, J. Volcanol. Geotherm. Res., 53, 275-287, doi:10.1016/0377-0273(92)90086-S

Orsi, G., S. de Vita, and M. di Vito (1996), The restless, resurgent Campi Flegrei nested caldera (Italy): Constrains on its evolution and configuration, J. Volcanol. Geotherm. Res., 74, 179-214, doi:10.1016/S0377-0273 (96)00063-7.

Orsi, G., L. Civetta, C. Del Gaudio, S. De Vita, M. A. Di Vito, R. Isaia, S. M. Petrazzuoli, G. P. Ricciardi, and C. Ricco (1999), Short-term ground deformation and seismicity in the resurgent Campi Flegrei caldera (Italy): An example of active block-resurgence in a densely populated area, J. Volcanol. Geotherm. Res., 91, 415-451, doi:10.1016/ S0377-0273(99)00050-5.

Rapolla, A., M. Fedi, and M. G. Fiume (1989), Crustal structure of Ischia-Plegrean geothermal fields, near Naples, Italy, from gravity and aeromagnetic data, Geophys. J. Int., 97, 409-419, doi:10.1111/ j.1365-246X.1989.tb00511.x.

Rosi, M., and A. Sbrana (Eds.) (1987), Phlegrean fields, Quad. Ric. Sci., 114(9), $175 \mathrm{pp}$.

Rundle, J. B. (1978), Gravity changes and the Palmdale uplift, Geophys. Res. Lett., 5, 41-44, doi:10.1029/GL005i001p00041.
Rundle, J. B. (1980), Static elastic-gravitational deformation of a layered half space by point couple sources, J. Geophys. Res., 85, 5355-5363, doi:10.1029/JB085iB10p05355.

Rundle, J. B. (1982), Deformation, gravity, and potential changes due to volcanic loading in the crust, J. Geophys. Res., 87, 10,729-10,744, doi:10.1029/JB087iB13p10729.

Saleh, B. (2002), Underground deformation measurements using new quarts instruments, paper presented at the 95th Annual CIG Geomatics Conference, Can. Inst. of Geomatics, Ottawa, Ont., Canada, 8-23 July.

Scandone, R., F. Bellucci, L. Lirer, and G. Rolandi (1991), The structure of the Campanian Plain and the activity of the neapolitan volcanoes (Italy), J. Volcanol. Geotherm. Res., 48, 1-31, doi:10.1016/0377-0273(91) 90030-4.

Talwani, P., and S. Acree (1984), Pore pressure diffusion and the mechanism of reservoir-induced seismicity, Pure Appl. Geophys., 122(6), 947-965, doi:10.1007/BF00876395.

Tarantola, A. (1987), Inverse Problem Theory, 613 pp., Elsevier, Amsterdam.

Tiede, C., K. Tiampo, J. Fernández, and C. Gerstenecker (2005), Deeper understanding of non-linear geodetic data inversion using a quantitative sensitivity analysis, Nonlinear Processes Geophys., 12, 373-379, doi:10.5194/npg-12-373-2005.

Todesco, M., and G. Berrino (2005), Modeling hydrothermal fluid circulation and gravity signals at the Phlegraean Fields caldera, Earth Planet. Sci. Lett., 240, 328-338, doi:10.1016/j.epsl.2005.09.016.

Tramelli, A., E. Del Pezzo, F. Bianco, and E. Boschi (2006), 3D scattering image for the Campi Flegrei caldera (Southern Italy). New hints on the position of the old caldera rim, Phys. Earth Planet. Inter., 155, 269-280, doi:10.1016/j.pepi.2005.12.009.

Usai, S. (2003), A least-squares database approach for SAR interferometric data, IEEE Trans. Geosci. Remote Sens., 41(4), 753-760, doi:10.1109/ TGRS.2003.810675.

Vasco, D. W., C. M. Puskas, R. B. Smith, and C. M. Meertens (2007), Crustal deformation and source models of the Yellowstone volcanic field from geodetic data, J. Geophys. Res., 112, B07402, doi:10.1029/ 2006JB004641.

Walsh, J. B., and J. R. Rice (1979), Local changes in gravity resulting from deformation, J. Geophys. Res., 84, 165-170, doi:10.1029/ JB084iB01p00165

Williams, C. A., and G. Wadge (1998), The effects of topography on magma chamber deformation models: Application to Mt. Etna and radar interferometry, Geophys. Res. Lett., 25, 1549-1552, doi:10.1029/ 98GL01136.

G. Berrino, Istituto Nazionale di Geofisica e Vulcanologia, Sezione di Napoli, Osservatorio Vesuviano, Via Diocleziano 328, I-80124 Naples, Italy.

A. G. Camacho and J. Fernández, Instituto de Geociencias, Facultad de Ciencias Matemáticas, CSIC-UCM, Plaza de Ciencias 3, E-28040 Madrid, Spain. (antonio_camacho@mat.ucm.es)

P. J. González, Department of Earth Sciences, University of Western Ontario, London, ON N6A 5B7, Canada. 